\title{
Study on the Expression and Causes of the Implication in Animal and Plant Patterns in Oroqen Decorative Patterns*
}

\author{
Xiaojie Zhou \\ Heihe University \\ Heihe, China 164300
}

\author{
Jian Huang \\ Heihe University \\ Heihe, China 164300
}

\begin{abstract}
The ancient and primitive natural worship, totemism and ancestor worship of the Oroqen people promoted the development of decorative patterns. It was a true portrayal of the Oroqen people in long-term struggle with nature. At the same time, a large number of decorative pattern materials also reflect the expectation and aspiration of a better life of Oroqen people. For a nation with no language or words, this is both the witness to the development of a nation and an important basis for the history of a nation's development. In order to preserve this valuable national cultural heritage forever, it is necessary to make an objective record of this national culture. The research on the implication of decorative patterns will objectively and comprehensively explain the survival culture of the ancient nomadic people from a new perspective and thinking. The study of the implication of the Oroqen ethnic decorative pattern is using a new perspective, a new concept and a brand-new approach to inherit and carry forward the national culture, which has important practical significance.
\end{abstract}

Keywords-Oroqen ethnic group; decorative patterns; implication

\section{INTRODUCTION}

The ancient and primitive natural worship, totemism and ancestor worship of the Oroqen people promoted the development of decorative patterns. It was a true portrayal of the Oroqen people in long-term struggle with nature. At the same time, a large number of decorative pattern materials also reflect the expectation and aspiration of a better life of Oroqen people. For a nation with no language or words, this is both the witness to the development of a nation and an important basis for the history of a nation's development.

Through the analysis of existing decorative patterns, in the decorative patterns of the Oroqen people, animal and plant patterns occupy a very important part. The Oroqen decorative patterns mainly consist of plant, animal and geometric patterns. The image of the people is rare. In some places, patterns sculpted with hunters and hunting postures can be seen. Figures of people are mostly the front side. However, the difference is the animal patterns are mostly

*Fund Project: This article is one of the achievements of Heilongjiang Art Science Planning Project "Research on the Inheritance and Application of Oroqen Decorative Pattern Design and Creation Thought" (Project No.: 2017D085). side face, and the figure of people is simple and beautiful. These patterns can fully reproduce the Oroqen people's living environment, which is the full expression of the Oroqen people's love and worship for nature. From the skillful generalization and abstract deformation, it can be seen that the Oroqen people have rich aesthetic taste.

\section{PLANT PATTERN}

The Oroqen people lived in the vast Khingan Mountains area for a long time. The lush forest and the dense vegetation in the mountains have become an important source for the Oroqen people to create these patterns. The plants patterns include grasses, vines, trees, and flowers, etc., leaf pattern, tree pattern, flowers, grass, petals, buds, flower buds, and peach-shaped patterns, etc. In the Oroqen language, dahurian rhododendron is the most beautiful flower, so among many plant patterns, dahurian rhododendron pattern is the most widely used flower pattern.

The Oroqen people "dahurian rhododendron" pattern is refined and elegant, with a quiet and idle posture, which is a unique pattern. For dahurian rhododendron, there are different names. Some people think it is the rhododendron, namely Azalea. Because the Great Khingan is located in the warm and cold temperate zone, spring comes later than that in the Central Plains. The fourth month of the lunar calendar is the season when the rhododendron blooms. Rhododendron is cold-resistant and short-lived, but its vitality is extremely tenacious. The flowers are plum-shaped in purple. Local people call it "Azalea", "rhododendron", "Dala", or "Dazi". The red azaleas in the land of Khingan are reflected in the mountains, which reminds people of the noble character of the Oroqen people, such as unrestrained, enthusiastic, uncontested, and fearless characters. There is also a saying that it is the Khingan lily that symbolizes the loyalty, purity, and love. The holy Khingan wild lily blooms in the green grass, and this flower often blooms in the season of the green grass. Although it is difficult to find out which kind of flower is dahurian rhododendron, what is sure is that its character is the same, which goes beyond its own ornamental value, and has extremely rich deep connotations.

The dahurian rhododendron is the symbol of beauty in the consciousness of the Oroqen people. Although the 
cultural spirit and aesthetic concept of each ethnic group are not the same, as the cultural theme of the decorative art, the pattern of the dahurian rhododendron is deeply loved by the Oroqen people. Because the dahurian rhododendron is full of the national cultural spirit and temperament, it has always been admired by the Oroqen people and has become the standard for the aesthetics and ideal of the Oroqen. Therefore, dahurian rhododendron is often used as a symbol of personality and style by the Oroqen people, which is closely related to the national cultural spirit and aesthetic consciousness. The dahurian rhododendron is a pattern art based on flowers. In the specific history and cultural atmosphere of the Oroqen people, the praise and love of flowers are not completely consistent. The early decorative patterns of dahurian rhododendron have been difficult to find for a number of reasons, and only a few recent modern works have been left.

Dahurian rhododendron decorative patterns abstract the wild flowers in an unconventional manner, and the basic shape is cross-shaped. The shape of its flowers is extremely abstract, giving people a sense of absurdity and bizarre. Deformation leads to a new shape that does not exist, reflecting the characteristics of strictness and regularity. Dahurian rhododendron represents the tenacity and noble sentiments of the Oroqen people, symbolizing the girl's beauty and purity as well as love and happiness. If the dahurian rhododendron is decorated on birch bark utensils, it means that the married girl will always be with her husband. It is such a flower character that reflects the personality ideals of the Oroqen people and is the moral norm and value standard of the Oroqen people's visualization and materialization. Therefore, it is also the basic goal of consciously constrained ethical awareness and pursuit.

In a certain sense, the content contained in art is concept. The decorative pattern is a way for the Oroqen to grasp the world iconically. The decorative pattern of dahurian rhododendron is constructed in a certain form and reflects a certain concept. At the same time, it is also a kind of pure expression:

- The auspicious theme of the decorative patterns and the integration of the spiritual elements in the patterns reflect the manifestations and essence of the auspicious moral concepts, which symbolize the behavior and will of the Oroqen peoples' goodness and beauty.

- The dahurian rhododendron contains the Oroqen traditional culture, which promotes the spirit of humanism. Its inheritance and development are more cultural and social.

- Dahurian rhododendron is one of the main contents of the Oroqen traditional folk custom pattern, including the essence of moral concept.

- The dahurian rhododendron standardizes the aesthetic and creative consciousness of the Oroqen people with its flower quality and cultural spirit. They use colorful and rich flower shape art to cultivate and enrich people's hearts.
The Oroqen flower plant decorative pattern is a manifestation of social civilization. It is in such a relationship of mingling with and inter-depending with culture that this art form has gradually matured from the budding era of ancient times; it has the opportunity to show the world its beautiful and unique elegance. The traditional cultural subject of the Oroqen aesthetic consciousness shows that this art form has a huge impact on the development of national culture and the national spirit. Its significance is farreaching and significant.

\section{ANIMAL PATTERNS}

Since the Oroqen people lived long-term hunting lives, they encountered a variety of beasts during the hunting process. Therefore, both men and women in Oroqen will observe various wild beasts. This observation is so meticulous that the observed images of wild animals have become a symbol that deeply mapped into the minds of Oroqen people, so they will turn the images of these animals into patterns or symbols and apply them to everyday objects. Most of the animal patterns are used in costumes and artifacts, including sheep horns pattern, horse pattern, deer pattern, bird pattern, butterfly pattern, wild geese pattern and other wild animals and bird insects.

The butterfly pattern is a symbol of beauty. Influenced by the flower and bird painting in Song Dynasty, the butterfly pattern began to prevail. The Oroqen people usually use the paper-cut applique to perform the butterfly pattern. The butterfly pattern is often accompanied by the entangled flower as the auxiliary pattern and the pattern composed of butterfly and the flower is embellished on the women's leather gloves.

In the performance of the butterfly pattern, the Oroqen people focus on the shaping and change of its demeanor in the modeling. The shaping is more natural and tends to faithfully depict the basic features of the object shape to achieve the imaginary effect.

The animal horn pattern is a symmetry pattern, including the moose horn, deer horn, and roe deer horn. It is a decorative pattern that reflects the original hunting and fishing life of the Oroqen people. We can see the existence of animal horn patterns on the stone implement and architecture of the primitive society. The animal horn represents prey.

\section{GEOMETRIC PATTERNS}

The geometrical pattern is the most common pattern on the Oroqen people's living utensils. For example, the pattern of water waves can be seen on the bowl. The birch bark's living utensils include birch bark buckets, birch bark boxes, birch bark cradle, and birch bark tub and so on. There are many geometric designs in these birch bark products, from which we can see the bold abstraction, exaggeration, and distortion of the things in nature made by Oroqen people, and the symbols produced by these changes is the refinement of art and the yearning for nature. For example, the common water wave pattern is the processing performance of water in 
the nature; cloud pattern, cloud waves pattern, and cloud roll pattern is the deformed manifestation of clouds in nature.

\section{ANALYSIS OF THE CAUSES FOR THE}

CHARACTERISTICS OF ANIMAL AND PLANT PATTERNS IN OROQEN DECORATIVE PATTERNS

\section{A. Living Environment Creates Themes and Forms of Decorative Patterns}

Although there are various kinds of sayings about the ethnic origin of the Oroqen people, most scholars seem to prefer that they are descendants of the Su Shen people. However, from the existing literature, it is difficult to clearly outline the clear and complete line of clues from the ancient Sushen to the present Elunchun. Because of the long-term residence in the mountains and forests, the design and decoration of decorative patterns are also dominated by natural flowers, birds and beasts. The themes of the Oroqen decorative pattern are distinctive. In addition to the later introduction of cloud pattern, hui pattern and other patterns, the rest of the patterns are the abbreviation of the living environment. Its themes and forms have distinctive geographical and original features.

\section{B. The Effect of Cultural Dissemination Form on Decorative Patterns}

According to statistics, the Oroqen people do not have its own ethnic language and uses the northern branch of the Manchu language family, namely the Tungusic language branch. In addition to the national language, many Oroqen people in the Qing Dynasty used Manchu. Since Republic of China, Chinese is gradually generalized. Especially after the settlement in 1953, there were even more people who used Chinese. Due to the ethnic characteristics, most of the Oroqen's cultural transmissions are realized through oral communication, so that there isn't a complete and systematic communication system, just like the Oroqen folk songs and dances. The Oroqen ethnic decorative pattern has no fixed form and has much randomness and contingency. Through some oral literature records, some information related to decorative patterns can be found. For example: In the lyrics of "Ohulande Hulan," it sings: "Flowers bloom on the banks of the river, like silver piling there. The crow's feather is good, and our earrings are made by imitating it. The magpie's wings look good, and our uppers are drawn according to it. The mouth of the Uzbek bird is pointed, and our boots are sewed based on it. It can be seen that the creation of the Oroqen decorative pattern is derived from nature and in line with nature.

\section{Production Lifestyle Determines the Characteristics of Model of Decorative Patterns}

- In the rough and simple decorative style, there is no lack of soft and delicate decorative patterns.

- The equal national concept makes the decorative pattern have a large creative space.

There is no apparent sense of hierarchy and hierarchy system between the Oroqen people like the Han and Manchu ethnic groups. When hunters return from hunting, not only their families can eat prey, but other members of the clan can help themselves as long as they need it. Therefore, in the creation process of decorative patterns, the different patterns don't indicate the differences in social status like the other nationalities, and there are not many dogmatic and rigid requirements. It also allows the creator to have a relatively large creative space, and even a lot of designs are improvised by the creators, like the folk songs of the Oroqen people.

\section{The Involvement of Foreign Cultures Has Created a Diversity of Decorative Patterns}

In the past, whether it was small-scale marriage integration or large-scale cultural integration, it all represented a nation's integration, and was a huge cultural progress. The involvement of foreign cultures has led to a diversified tendency in the modeling and implication of the Oroqen decorative pattern. However, the cause of this all stems from two reasons:

1) Marriage: When the Oroqen people were not separated from the hunting life, their marriage was basically confined within the nation, and only a few people married Ewenki or Daur people. The inter-ethnic intermarriage has led to a greater development of decorative patterns. Drawing on external cultures, the decorative patterns of the Oroqen people have new content in the subject and form. Based on the traditional patterns such as bears, tigers, fire, and water, dragon pattern also appeared.

2) Trade: The Oroqen people have always lived the self-sufficient life and there are few exchanges of goods. In the 17th century, after the reunification of the Qing dynasty, trade gradually emerged, which led to the appearance of fabrics, ropes, and string in the decorative patterns of the Oroqen people. At the same time, cloud pattern, Hui pattern, and eight treasures pattern also appeared in the artifacts of Oroqen tribe.

\section{CONCLUSION}

The Oroqen decorative pattern has strong ethnic characteristics, and it is extremely rich in ethnic characteristics in terms of form and implication. In the selection of themes, they still persist in the principles of coming from nature and higher than nature to continue the innovation and development. Due to the ethnic habits of the Oroqen people, they have less contact with the outside world, so they have a strong primitiveness and originality on the decorative patterns. In addition, the ever-changing living environment has continuously enriched and changed the decorative patterns and made it maturer. Without the limit of many ideas, a large number of pattern works reflecting the life habits and aesthetic preferences of Oroqen people were created. These works are primitive and original without intervention of outside ideology. They have made an indelible and important contribution to developing the content and form of pattern with national characteristics in future. 
The implication of the decoration pattern of the Oroqen ethnic group is the mixture of the Oroqen people's awe to the power of nature, the belief in the gods, and longing for a better life. Due to the characteristics of the nation's life, this kind of mixed thinking gradually became the most important ideological criterion that influenced the implication of decorative patterns. There are also common places and differences between Oroqen people and other ethnic groups, which highlights the primitiveness and simplicity of the ancient people, reproduces the thinking form and connotations of the ancient nationalities and provides a basis for studying the shapes and meanings of ancient ethnic decorative patterns.

\section{REFERENCES}

[1] Wang Weihua. Totem Culture of Oroqen: Ancient Fantasy and Reliance of Human Beings[J]. Heilongjiang Social Sciences, 2008(02). 王为华. 鄂伦春族图腾文化: 人类远古的幻想和寄托 $[\mathrm{J}]$. 黑龙江社会科学, 2008（02）.

[2] Wang Duan. Analysis of Oroqen traditional patterns [J]. Journalism lover, 2010 (05). 王端. 浅析鄂伦春族传统图案 [J]. 新闻爱好者, 2010 (05). 